\title{
Studies on the Synthesis of Nitrogen-Ring-Compounds (X).
}

\section{Group: Synthesis of Indole-Derivatives (I).}

\section{A New Synthesis of Indole.}

\author{
by \\ Shigehiko Sugasawa, Isao Satoda and Jiro Yanagisawa \\ [From the Pharm. Instit. of the Imperial Univ. of Tokyo.]
}

(Received February 7 th. 1938.)

For the synthesis of indole-derivatives there are many methods described in the literature, among which that by E. Fischer is most extensively used. For indole itself, however, none of the known methods, except that by Prof. R. Majima, is of practical use, thus making indole difficultly accessible. Majima and his coworkers succeeded in preparing indole in quantity by treating aniline and acetylene at higher temperature (Majima, Unno and Ono: B. 55, 3854, 1922). They obtained several by-products besides indole, but the isolation of the latter from the former seems to offer no special difficulty.

One of the present authors and K. Kakemi have succeeded in preparing tetrahydroquinolene and therefore quinolene by the following sequence of reactions without any difficulty (J. Pharm. Soc. Jap. 57, 170, 1937).

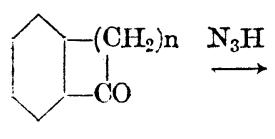<smiles>C1CCC2NCCCC2C1</smiles>

III<smiles>C1CCC2NOCCCC2C1</smiles>

I<smiles>C1=CC2CCCCC2N=CCC1</smiles>

IV<smiles>[CH]1S[As]CC2CCCCC12</smiles>

II<smiles>C1CCC(NC2CCCCC2)CC1</smiles>

$\mathrm{V}$

( $n=2$ for quinolene)

If the above reactions might be available also for oxindole ( $I, n=1)$, which is readily obtainable by Stollè's elegant method (J. pr. Chem. (2), 128, 1, 1930), a new route should lead to indole, and this was really the case. 
We are now extending the synthesis to various oxindoles and moreover since indolines became easily accessible by this new route, varieties of their derivatives are the objects of our forthcoming investigation, hoping to find compounds of any practical use.

\section{(Experimental)}

Oxindole (I. $n=1$ ): This was obtained in $85 \%$ yield when 1 part of chloroacetoanilide was melted with 1.8 parts of $\mathrm{AlCl}_{3}$ at $225^{\circ}$, while from the mixture of equal parts of the two substances no oxindole was formed under variety of conditions (cf. Stollè : loc. cit.).

Thioxindole (II. $n=1$ ): After many experiments for converting oxindole into thioxindole, the following method proved to be most suitable for the purpose.

Oxindole (4 g. $1 \mathrm{~mol}$.) and $\mathrm{P}_{2} \mathrm{~S}_{5}(1.4 \mathrm{~g} .1 / 5 \mathrm{~mol}$.) were thoroughly mixed and the whole was heated under pure xylene $\left(\mathrm{ca} .20 \mathrm{cc}\right.$ ) at $100-110^{\circ}$ for half an hour. The resulting reddish-brown solution was filtered while hot and the residue was extracted with the same solvent. From the combined extract yellow dice separated on standing. Yield ca. $3 \mathrm{~g}$ or $70 \%$ of the theoretical. When purified from benzene, it separates forming yellow dice of $\mathrm{d}$. p. of $145^{\circ}$. It dissolves slowly in caustic alkali solution, but the original substance cannot be reprecipitated therefrom by acid. The crude substance was directly submitted to reduction.

Indoline (III, $\mathrm{n}=1$ ): The crude thioxindole ( $1 \mathrm{~g}$.$) was suspended in alcohol (15 \mathrm{cc}$.) and $25 \%-\mathrm{H}_{2} \mathrm{SO}_{4}\left(60 \mathrm{cc}\right.$.) and was reduced electolytically with lead-cathode (ca. $\left.100 \mathrm{~cm}^{2}\right)$, to which a current of $10 \mathrm{amp}$. was applied for 4 hours at about $30^{\circ}$. After removing alcohol from the cathodic solution, water was added to the residue and the whole was extracted with ether to remove non-basic substance if present. By basifying the acid solution, ca. $0.5 \mathrm{~g}$. basic substance was isolated which came over at $70-75^{\circ}$ under $2 \mathrm{~mm}$. as faint yellow viscous oil. From the melting point $\left(133^{\circ}\right.$, cf. B. 44, 2160, 1911) and the results of analysis of the benzene-sulfonic derivative, this base was proved to be indoline $\left(\mathrm{C}_{14} \mathrm{H}_{13} \mathrm{O}_{2} \mathrm{NS}\right.$ requires $\mathrm{C}, 64.9, \mathrm{H}, 5.0$; Found $\left.\mathrm{C}, 64.7, \mathrm{H}, 5.0\right)$.

Indole $(\mathrm{V})$ : Hoshino's method for dehydrogenating tetrahydrocarbazoles (Bull. Chem. Soc. Jap. 11, 218-20, 1936) was successfully applied for the present case.

Indoline (0.5 g.), cinnamic acid (0.65g.) and Pd-black (0.05g.) were melted to-gether at $120-125^{\circ}$ for 5 minutes, when reddish melt was obtained. This was extracted with 
ether. The ethereal solution was washed with dilute soda-solution and then with dilute $\mathrm{HCl}$, dried and evaporated. The residue solidified to a dirty greenish mass of characteristic odour and melted at $52^{\circ}$ alone or admixed with an authentic sample of indole and gave both pine-shaving and Ehrlich's tests. For further identification the corresponding triphenylmethyl-derivative was prepared according to Funakubo (B. 69, $2129,1936)$, the melting point of which stood at $211^{\circ}$ and was not changed, when admixed with an authentic specimen. $\left(\mathrm{C}_{27} \mathrm{H}_{21} \mathrm{~N}\right.$ requires $\mathrm{C}, 90.25, \mathrm{H}, 5.85 ;$ Found $\mathrm{C}$, 90.6, H, 5.6).

\section{Berichtigung.}

Jahrg. 58, (1938), Heft 1, S. 16, Z. 4 v. o. liess „Acetylcinobufagin“ statt „Cinobufagin". 


\section{含窒素異性環狀化合體の合成研究 $(\mathbf{X})$ 第三類 インドール列化合體の合成研究 インドールの一新合成法に就て}

$\begin{array}{llll}\text { 菅 } & \text { 䍜 } & \text { 重 } & \text { 彦 } \\ \text { 里 } & \text { 田 } & \text { 勳 } \\ \text { 節 } & \text { 澤 } & \text { 二 }\end{array}$

(昭和 13 年 2 月 9 日梁理)

S. Sugasawa: Synthese der N-haltigen Hetero-Ringe (X)

III. Gruppe: Synthese in den Indol-Derivaten

S. Sugasawa, I. Satoda u. J. Yanagisawa: Nene Synthese von Indol.

Indol一誘導體の中には動植物界に座出するものに與味あるもの多し，而して一般 Indol 唀導 體の合成法としては E. Fischer 氏法を始めとして諸種の方法記载さる。されど Indol 自身の

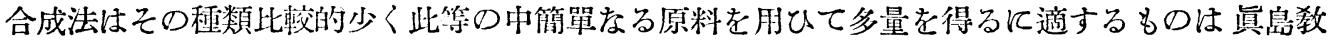
授等の方法なるべし. 師ち本法は Anilin 上Acetylen よりするものにして同時に Indol 以外の 化合物を傍生するも之等より Indol 存分離する事は困難に非るが如し．[R. Majima，T. Unno u. K. Ono: Ber. 55, 3854 (1922)].

著者等の一人は星に掛見上次式に示す如き徑路に依りて此較的簡單に途中何等激しき操作を 用ひずして Chinolin t合成する事を得たり [䊾學雜誌：57，745-47（昭和十二年）]<smiles>O=C1CCCCC1CO</smiles><smiles>CC(C)C</smiles>

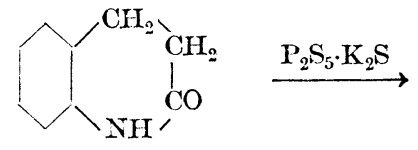<smiles>C1CCC2NCCCC2C1</smiles><smiles>C1CCC2NCCCC2C1</smiles><smiles>C1CCC2CCCC3CCCCC(C1)C23</smiles>

而して最後の Dehydrierung は既に赤堀氏 [Bull. Chem. Soc. Jap. 4, 198 (1928)] 亿依て完 成されし所なりとす。

從て上記反應を Oxindol- 類に應朋すれば簢單に種ぬなるIndolin- 誘導體を得へくく更に之れ を脫水素化する事を得ば Indol一誘導體に到達する事難からざる可し.而して原料なる Oxindol一 
類は Stollé 氏法に依り Anilin 及び其の誘導體より極めて容易に製し得るものなり。

低て余等は本工程に依り先づ Indol の合成を試みたるに賽驗之部記载の如く極めて圓滑に

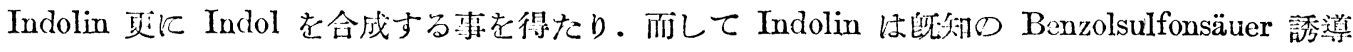
體とし义 Indol は Funakubo 讵 [Ber. 69, 2129 (1936)] 飞從ひえれを N-Triphenyl-methyl-

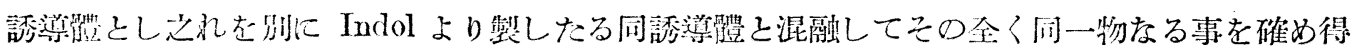
たり。

而して IndolinょりIndol に到る脫水素区應の䉆めには余等の經驗したる限りに於ては水溶

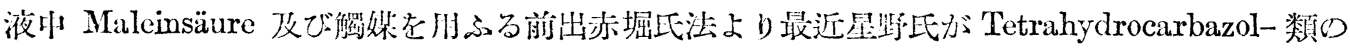

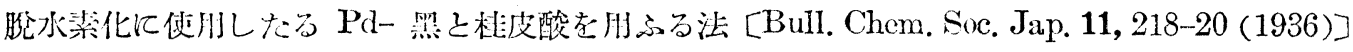
の方遥江曼奶なる維染を與へたり。

本 Indol 合成法を式示すれば下の如く余等は玆に Indol の合成法に記成するに足る一新法老

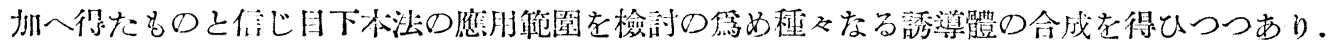

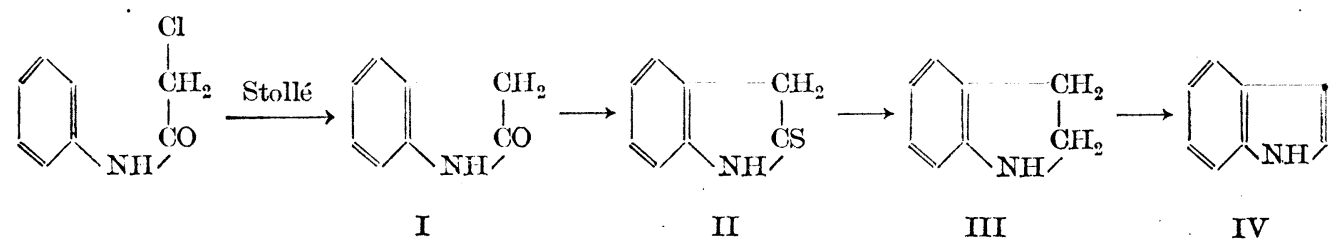

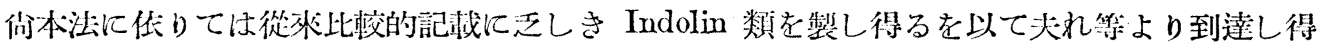
る程はなる化命物の周成をも行ひつつ古り。

\section{䔈 驗之部}

Oxindol : (I) Stollé [J. pr. Chem. (U) 128, 1 (1930)]に低れば Chloracetanilid を同量の $\mathrm{AlCl}_{3}$ と混 じ $225^{\circ}$ 附近に加熱して $85 \%$ 程度の得望な以て Oxiodol を得たる記载もるも余等の場合に於ては充分注意

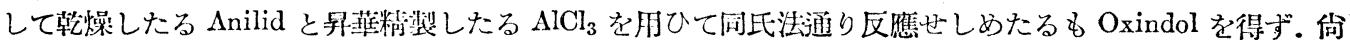
区㕍溫度及で洔間を種々變化せしめたるも其目的を達し得ざりしも最後に $\mathrm{AiCl}_{3}$ の過剩を用ひ原料 Anilid

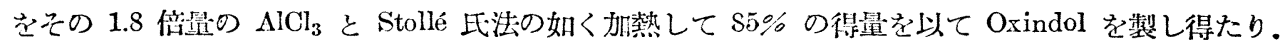

Thioxindol：（II）上に得たる Oxindol より Thioxindol を得る目的を以て溶濟の種類 $\mathrm{P}_{2} \mathrm{~S}_{5}$ 及び $\mathrm{K}_{2} \mathrm{~S}$ の量を種々變化せしめ加熱泪度及び時間に就ても種々なる赛驗を行ひし結果此の場合は $\mathrm{K}_{2} \mathrm{~S}$ を用ひず次の 如き條件下に於て相當の成續を以て Thioxindol を製し得たり。

Oxindol 4g $(1 \mathrm{Mol})$ と $\mathrm{P}_{2} \mathrm{~S}_{5} 1.4 \mathrm{~g}(1 / 5 \mathrm{Mol})$ とを密に混じ之れに無水 Xylol 約 $20 \mathrm{cc}$ を加へ全體を攪

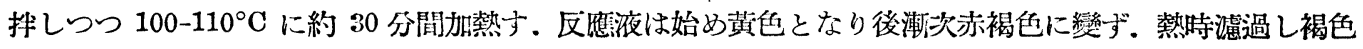
残渣は再三無水 Xylol に依り抽出し液を放冷する時は美麗なる黄色䯓于狀結晶を析出す．母液を濃縮して 倘少量同一物賀を得. 得量約 $3 \mathrm{~g}$, 理覦數の約 $70 \%$ に當る. Benzol より再結晶する時 Zp. 145ํ の結晶と して得られ. 本品は苛性ソーダ溶液に徐々に溶解す。アルカリ性溶液を酸性となす時は再び析出するす不 純にしてアルカリ性溶夜中にて變化を受くるが如し、本品は分析を行はず直ちに之れを還元に附したり。

Indolin (2,3-Dihydro-indol)：（III）上に得たる Thioxindol $1 \mathrm{~g}$ を酒精 $15 \mathrm{cc}$ に溶解し $25 \%-\mathrm{H}_{2} \mathrm{SO}_{4}$ 
$50 \mathrm{cc}$ を加へて侩極液となし präparieren したる鉛除極を用ひ陽極液として $20 \%-\mathrm{H}_{2} \mathrm{SO}_{4}$ 陽極として鉛を用 ひ $10 \mathrm{Amp}$. (陰極面積約 $100 \mathrm{~cm}^{2}$ ) $30^{\circ}$ にて電解還元を行ふ.4時間後電流を絶ち減圈下に酒精を溜去し殘渣

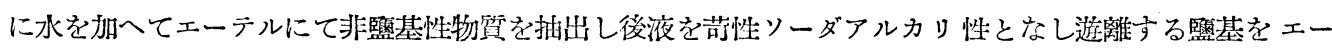
テルに取り夜を乾燥，溶劑を溜去して残渣を減厴蒸溜に附するに $\mathrm{Kp}_{2} 70-75^{\circ}$ の溜分約 $0.5 \mathrm{~g}$ を得たり。 少量にして再溜精製困蜼なるを以てその一部を常法に依り Benzolsulfochlorid と作用せしめたるに交獻記 戴〔Ber. 44, 2160 (1911)] と同一の Fp. 198。 を示す Benzolsulfo-indolin を得たり.

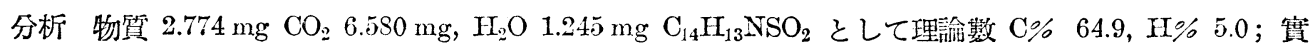
驗数 $\mathrm{C} \% 64.7 ; \mathrm{H} \% 5.0$.

Indol：（IV）上に得たる Indolin の脫水素洼として先づ赤堀氏に從ひ Maleinsüure 水溶液中 Pd- 黑 と煮沸する法を試みたるも良好なる結果を得ず。依て星野氏が Tetrahydrocarbazol に肋ひたる法 (loc. cit) を應用したるに目的物 Indol を得たり。

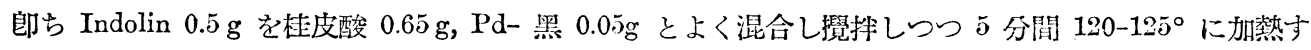
る時熔融物は赤色となり冷後固結して污綠色となる之をエーテルにて抽出し $5 \% \mathrm{Na}_{2} \mathrm{CO}_{3}$ 液にて洗ひ 次に稀監酸にて振る時エーテル液は微黄色となる，芒确にて乾燥捘溶煤を溜去する時は特異の臭氣を有

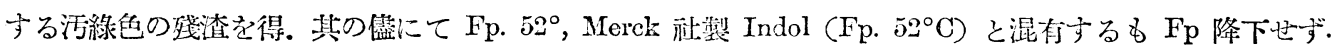

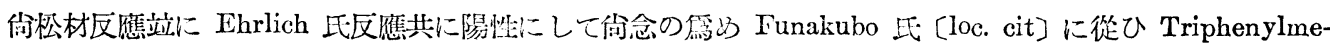
thyl一誘導體を製したるに Fp. 211にして別にIndol より製したるものと混融するも Fp. の降下を見ず.

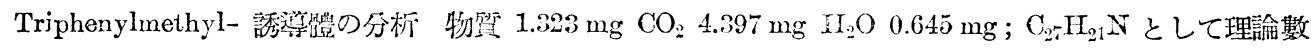
$\mathrm{C} \% 90.25, \mathrm{H} \% 5.85$; 䆩驗数 $\mathrm{C} \% 90.6, \mathrm{H} \% 5.6)$

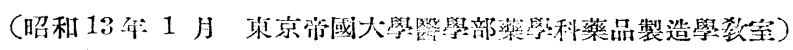

\section{アンモニウムアマルガムの利用䂧究 (第二報) Benzaldehyd に對するアンモニウムアマルガムの作用}

高木 誠 司
上田 武 雄

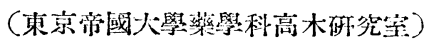

(昭和 13 年: 2 月 7 日受理)

緒言

著者等は第一報》に於てアンモニウムアマルガムの反應利胕法に就て發表し 叉アンモニウム アマルガムの性能に對して理論的の根據を與へた。著者等は之が反應利用の第一步として 